\title{
Perceptual Confidence: A Husserlian Take
}

\author{
Kristjan Laasik ${ }^{1}$ \\ (Penultimate Version)
}

\begin{abstract}
In this paper, I propose a Husserlian account of perceptual confidence, and argue for perceptual confidence by appeal to the self-justification of perceptual experiences. Perceptual confidence is the intriguing view, recently developed by John Morrison, that there are not just doxastic confidences but also perceptual confidences, i.e., confidences as aspect of perceptual experience, enabling us to account, e.g., for the increasing confidence with which we experience an approaching human figure, while telling ourselves, as the viewing distance diminishes, "It looks like this just could be Isaac", "It looks like this is probably Isaac", "It looks like this is almost certainly Isaac". I first present my Husserlian account with a focus on the notion of fulfillment, and the idea that the contents of perceptual experience are fulfillment conditions. I then show that this account can be complemented by PC. Finally, I develop a focus on the idea of perceptual selfjustification, diverting the perceptual confidence debate from its pre-eminent concern with the relations between perceptual and doxastic confidences, and present an argument to the effect that there are perceptual confidences.
\end{abstract}

\footnotetext{
${ }^{1}$ Affiliation: Department of Philosophy, School of Humanities, Zhejiang University, Hangzhou, China. Correspondence: Kristjan Laasik, Department of Philosophy, School of Humanities, Zhejiang University, 148 TianMuShan Rd., Hangzhou, Zhejiang 310028, China.

Email:klaasik@gmail.com
} 


\section{Introduction}

Suppose that you take yourself to be seeing a distant human figure walking towards you. You tell yourself, "It looks like this just could be Isaac". When the figure is already closer, say, 50 meters away, you think to yourself, "It looks like this is probably Isaac". Finally, when the figure is only a few meters away, you take it to be certain that this is Isaac. It would be relatively uncontroversial to describe this situation just in terms of your increasing levels of confidence at the level of belief, also known as doxastic confidence (DC), but John Morrison has recently advanced the novel, more contentious idea that this example-which he uses to introduce his discussion - may also reflect an increase in perceptual confidence (PC), taking it thus to support "[perceptual confidence], the view that our perceptual experiences assign degrees of confidence" (Morrison 2016, p. 15). He chiefly articulates and defends this view in opposition to what he regards as the most plausible alternative, viz., "[post-perceptual confidence], the view that while our perceptual experiences represent external objects and their properties, they do not themselves assign degrees of confidence" (Ibid.). On this view, there are only doxastic confidences, which may be caused or justified by perceptual experiences.

In this paper, I wish to broaden the burgeoning PC debate by proposing a Husserlian account of PC, and arguing for PC by appeal to the self-justification of perceptual experiences. I will occasionally reference Morrison's views, as well as criticisms thereof, but mainly so as to show, by way of contrast, how my approach enables us to completely re-cast the debate. Morrison, as we have seen, introduces PC by conceiving of it as closely aligned with, but distinct from, DC. Our approach is different in that we give close heed to aspects of the perceptual experience itself, instead of seeking to mine any putative relationship between PC and DC. 
At the core of the Husserlian view is the notion of fulfillment. For an elucidation by example, consider a situation where you are perceptually experiencing an apple. Your experience, now, of the apple's front side is considerably different from your experience of its back sideassuming that you can, indeed, be legitimately said to be experiencing its back side. To label this difference, yet to be given closer consideration, let us call the experience of the front side "full" and the experience of the back side "empty". To mark the transition from empty to full experience, such as when I pick up the apple and turn it around, let us deploy the term "fulfillment". Fulfillments can be due not just to my changing my position relative to the object, and the resultant unconcealment, but also to a great variety of other changes in the perceptual circumstances, including changes in the angle of vision (with regard to parts that are already in view), improvements in lighting conditions, and changes in the intervening medium, e.g., the lifting of a fog. Fulfillments can be had in regard to specific perceptual properties, such as color or shape, and they can come in degrees, as when the fog between me and Isaac gradually clears, or when I slowly turn the apple in hand as I observe it, revealing more aspects of its shape.

I will be elaborating the idea of fulfillment in two main regards. On the one hand, I will be working towards the idea of perceptual self-justification, by articulating a view on which the notions of fulfillment, and fullness, are connected with the notions of perceptual content, and evidence. In a nutshell, the idea is that perceptual experiences, as they gain fulfillments, provide justification to themselves, and not only to perceptual beliefs. On the other hand, I will associate the changeable levels of fullness with PC. These two strands will finally be interconnected in my argument for PC. 
2.

Going beyond the remarks that I have already made on the topic of fulfillment, I will now argue that perceptual contents can be regarded as fulfillment conditions, and make suggestions as to how this may shape our perspective in regard to the identity of perceptual experiences through time. ${ }^{\mathrm{i}}$

Having already introduced the ideas of fullness, emptiness, and fulfillment, let us further accept that our experience of the emptinesses is due entirely to more or less tacit perceptual anticipations, say, of the ways the object's shape would look from different vantage points, or the ways its color will look under changed lighting. Insofar as such anticipations set forth the conditions under which the experience can gain fulfillments, we can say that the anticipations instantiate the fulfillment conditions of the perceptual experience. When the experience continues as anticipated, we experience fulfillments, and when it continues in a way that runs counter to anticipation, we experience a disappointment, the opposite of fulfillment. Just as in the former case we say that it was not just the anticipations that were fulfilled, but also the perceptual experience itself, so, in the latter case, we speak not just of the anticipations', but also the perceptual experience's being disappointed. As I have already noted, there is experiential emptiness with regard to many different aspects of the objects that we experience. The emptiness is really quite pervasive: in addition to the way that an object appears to the perceiver now, there are always the numerous experienced possibilities of how it might appear. We can therefore take the next step and claim that objects and their perceptual properties are, indeed, present to us in terms of such anticipated possibilities of fulfillment, and that the contents of perceptual experiences are fulfillment conditions, instead of, say, accuracy conditions, as they are regarded by one kind of mainstream view in the philosophy of perception. ${ }^{\text {ii }}$ 
The fulfillment conditions of which we speak are captured by conditionals, e.g., "If I picked up the long-lost tennis ball from the grass and turned it around, I would see a discolored area on the back side". iii These conditionals would, first and foremost, need to be future-oriented ones, not counterfactual ones, given that they are to capture anticipations which can be fulfilled or disappointed in the future course of the experience. By contrast, the truth or falsity of counterfactual conditionals could not be thus directly established in the further course of the experience, insofar as they contain an antecedent that is assumed to be false, e.g., "If I were now picking up and turning around the tennis ball (instead of what I am actually doing), I would see a discolored area".

Among the experiential possibilities captured by such conditionals, we may, following Husserl, distinguish between the motivated and the unmotivated ones. There are, of course, a great many ways in which my experience could turn out, and I do have an implicit sense of these multitudinous possibilities, but there is also a much narrower range of possibilities or scenarios that I would realistically expect to materialize. E.g., given the way that I am moving, and given the way that my experience is unfolding in this moment, I have a lively anticipation that things could turn out a certain way, e.g., that the tennis ball could reveal itself as having a yellow back side. ${ }^{\text {iv }}$ In explaining this distinction to his academic audience, Husserl even phrases it as a distinction between "real" and "unreal" possibilities (Husserl 1997, § 84). Now, I wish to make the point that insofar as fulfillment-conditional content captures something like one's perspective of the object, while being sensitive to the distinction between motivated and unmotivated possibilities, it yields something like a sense of an experiential trajectory and locates the perceiver on this trajectory. The experience is coming from somewhere and it is going somewhere, with certain fulfillments already attained and a line of others still outstanding. 
This view of contents invites a certain perspective of the identity of perceptual experiences through time. Suppose that I have perceptual experiences E1, E2, and E3, one after another, of different "sides" of a tennis ball. If we conceived of the contents of these experiences in terms of accuracy conditions, we could recruit them in support of some perceptual belief or beliefs about the tennis ball. Insofar as they are experiences of the tennis ball, any one of them could, on its own, support some suitably chosen belief about the tennis ball. However, we also have the option of invoking them additively, to consider what cumulative support they might give a belief, e.g., "There is a tennis ball in front of me".

However, consider how our perspective will change if we conceive of these experiences in terms of fulfillment-conditional content. If I now reach for E2, to support the belief, "There is a tennis ball in front of me", it is not just that while E2 provides it some amount of support, I could garner more support for it by also drawing upon E1 and E3. Instead, it seems that we cannot conceive of E2's supporting the belief, without also conceiving of E1's and E3's supporting the belief, insofar as E2 implicates both, retaining the fullness of E1 as aspect of its content, and emptily projecting the fullness of E3, as another aspect of its content. Notice that the cumulative support that these three experiences provide the belief, is not merely additive but implicates their temporal ordering. If, in your imagination, you ran through these experiences in the reverse order, they could yield not fulfillments but, instead, disappointments, or else just a very confusing experience, e.g., insofar as E2 projects precisely the fullness of E3, and not of E1. Moreover, if we conceive of these experiences in terms of fulfillment-conditional content, then not only are we led to consider all three experiences in a certain order, but will also be led to consider the transitions among these experiences, from E1 to E2 to E3. Fulfillment-conditional content is, first and foremost, the content of continuous, uninterrupted experiences, in the sense that the retentions and 
projections, say, of E2, implicate experiences immediately before and immediately after it. So, supposing that E2 does not immediately transition into E3, we would need to make sense of it in terms of further fulfillment conditions that also provide for an intermediate phase, setting forth the characteristics of the transfer from E2 to E3. E.g., the transition from experiencing the front side to experiencing the back side could take place across the trajectory of an uninterrupted lateral view, or involve interruptions of which we can somehow make sense, e.g., in terms of a temporary occlusion of our tennis ball by another object.

In view of all this, I think that the two views of content invite different perspectives in regard to the identity, and identification, of experiences that change through time. ${ }^{\mathrm{v}}$ If we take contents to be accuracy conditions, then it is "natural" to speak of E1, E2, and E3 as being three different experiences. But if we regard contents as fulfillment conditions, then it is helpful to speak about them as being phases of one single experience, to ensure that we do not lose sight of the diachronic connections which we have just elucidated.

3.

This Husserlian view can be developed into a view which involves PC. It is a view on which PC is associated with evidence. ${ }^{\mathrm{vi}}$ Alternatively, someone might draw upon the ideas discussed in the previous section, to put forward a kind of un-Husserlian view, according to which somebody can have a perceptual experience and achieve various fulfillments, but be entirely oblivious to the evidential significance of these fullnesses. Certainly, some fullnesses are required in order for something to visually strike me as being an apple, and in order for me to continue to have the perceptual experience of an apple, but it might be said that such fullnesses need not yet 
be appreciated as evidence for there being an apple, absent some kind of deliberation of their evidential significance.

On the Husserlian view, however, fullness always amounts to evidence, and fulfillments always yield evidence. Husserl regards perceptual fullness as paradigmatic case, but extrapolates the idea to other kinds of intentional experiences, including ones directed to abstract objects. Indeed, every kind of intentional experience is associated with kinds of evidence which could support it by bringing the pertinent object or objectivity to fullness, which he also refers to as original givenness or self-givenness, "The concept of any intentionality whatever-any lifeprocess of consciousness-of something or other-and the concept of evidence, the intentionality that is the giving of something-itself, are essentially correlative" (Husserl 1969, p. 160). Relatedly,

Category of objectivity and category of evidence are perfect correlates. To every fundamental species of objectivities - as intentional unities maintainable throughout an intentional synthesis and, ultimately, as unities belonging to a possible "experience" — a fundamental species of "experience", of evidence, corresponds, and likewise a fundamental species of intentionally indicated evidential style in the possible enhancement of the perfection of the having of an objectivity itself (Ibid., p. 161).

However, this extension of the idea of fullness to other kinds of intentional experiences, which surely raises many issues of its own, need not concern us here. What matters to us is that on the Husserlian view, perceptual experience always involves a kind of appreciation of the fullness as evidence, and can therefore be said to be responsive to evidence, including when fulfillments yield increases in the levels of fullness, and when a disappointment undercuts the line of fulfillment that one has been pursuing. For this is precisely what a disappointment does: it not merely rebuts a line of evidence by supplying some evidence to the contrary, but discredits the entire line of evidence, insofar as it was presumptive in nature, and projected to continue into the future. The fullnesses already attained will now be re-interpreted, and incorporated into a new line of evidence. A modification "takes place retroactively in the totality of the preceding series", e.g., as "the earlier 
apprehension, which was attuned to the harmonious development of the "red and uniformly round", is implicitly "reinterpreted" to "green on one side and dented" (Husserl 1973, p. 89).

From accepting this view, it does not follow that we need accept PC. Instead, I believe that the view enables us to regard perceptual experiences either in terms of PC or not. I would further suggest that it also enables us to regard some perceptual experiences as involving PC and others as not. To see this, let us first consider the kinds of perceptual experience which do not involve PC. It would seem that there are perceptual experiences that are epistemically conservative in the sense that in having them, we just take the object to be, e.g., an apple, and are not at all open to any alternative possibilities, and have even no real sense of any alternative possibilities. Even if we do have some sense of the alternatives, we certainly do not experience them as motivated possibilities, to use Husserl's term. We hang on to the experience tenaciously, unless a disappointment shatters its content. On the other hand, we may have a perceptual experience where we do have a sense of, and are open to, specific alternatives. Thus, when I take myself to be seeing a distant human figure walking towards me, I may be open to the possibilities of its being either Isaac, Aaron, or David, or to the possibilities of its either being Isaac or not being Isaac. On our view, my experiential openness to these possibilities needs to be accounted for in terms of anticipations and fulfillment conditions, e.g., to the effect that that if the figure approaches, I will be able to have a closer look at certain details, which may reveal him as being any one of these three people.

Indeed, Husserl distinguishes between these two kinds of perceptual experiences, with the aim of accounting for the origins of our concepts of possibility and probability. In his example, the available evidence allows for two possibilities, and he further envisions the experience in terms of 
there being two competing apprehensions, viz., of a man and of a mannequin, either of which may displace the other at intervals,

One and the same complex of sense data is the common foundation of two apprehensions superimposed on each other. Neither of the two is canceled out during the period of the doubt. They stand in mutual conflict; each one has in a certain way its own force, each is motivated, almost summoned, by the preceding perceptual situation and its intentional content. But demand is opposed to demand; one challenges the other, and vice versa. In doubt, there remains an undecided conflict. Since the empty horizons constitute objectivity only in unity with the common intuitive core, we accordingly have, as it were, a bifurcation of the original normal perception, which in unanimity constituted only one sense, into a double perception. They are two perceptions, interpenetrating each other by virtue of the content of their common core. And yet not really two, for their conflict also implies a certain reciprocal displacement. If the one apprehension takes possession of the common intuitive core, if it is actualized, then we see, for example, a man. But the second apprehension, oriented toward the mannequin, does not become nothing; it is suppressed, forced into the background, deprived of its power. ...

The doubling is therefore not really a doubling of [distinct] perceptions... (Ibid., p. 93). ${ }^{\text {vii }}$

However, Husserl clarifies that even if either apprehension dominates, "the mode of belief

and, in consequence, the mode of being are essentially changed" (Ibid.), in the sense that, "[i]nstead of being present to consciousness as simply there, as in normal perception, which runs its course unambiguously and at the same time harmoniously, [the object] is now present to consciousness as questionable, doubtful, disputable... (Ibid.). To be clear, in speaking of a "belief”, Husserl is in this context speaking of an aspect of the perceptual experience- this entire discussion is, by his lights, concerned with "pre-predicative experience", not with "predicative thought". viii Husserl's claim is that we can, already at this level, have a sense of possibility, and, indeed, probability, which he explicates, pertinent to "possibilities for which something speaks", as "the weight which belongs to the presumptions of being" (Ibid., pp. 95-96). ${ }^{\text {ix }}$

We have thus followed Husserl in incorporating PC into our fulfillment-based account of perceptual experiences. It is interesting that while we have developed an account that conceives of perceptual contents as fulfillment conditions, Morrison, in exploring the various upshots of PC, 
contends that $\mathrm{PC}$ is incompatible with the widely-accepted views that contents are accuracy conditions, and that there is a fundamental and sharp distinction between veridical and illusory experiences. He invites us to consider a case where one has perceptual experiences which assign various confidences to several alternatives, viz., that a certain ball is $6,7,8$, or 9 meters from one's head. He points out that if we consider pairs of such perceptual experiences, obtained by varying the number of alternatives in either, the levels of confidence assigned to the alternatives, and the weights of the different alternatives (considering how far off the mark they may turn out to be), it becomes clear that there is no one "objective" way of calculating the level of accuracy of these experiences, and hence of establishing which one of the two is the more accurate. But from this it follows, according to Morrison, that there is no one way of ordering our experiences based on levels of accuracy, so as to draw a line between the veridical and the illusory experiences (Morrison 2016, pp. 39, 43).

Morrison is basically arguing that our failure to compare these different experiences for accuracy is indicative of the absence of objective standards of accuracy, i.e., accuracy conditions, for such experiences. Would our fulfillment-conditional view run into such problems? We would now be comparing the different experiences not for accuracy but for fulfillment, or change in fullness. We could, say, take experiences which assign different levels of PC to different distances of the ball, while being otherwise as similar as possible, and envision their unfolding in similar ways, yielding fulfillments (or disappointments) and concomitant changes in levels of PC (and perhaps also some of the alternative possibilities' being eliminated, and others' entering our purview). Suppose that, at the end of it, we are somehow led to conclude that there is no principled way of conducting such a quantitative comparison, so as to produce an ordering of the experiences, based on change in the level of fullness. Might we be led to conclude that there just are no 
fulfillment conditions? My answer is that we could not draw such a conclusion, insofar as we have allowed that there are, in fact, fulfillments, and from this alone it follows that there are empty anticipations, instantiating fulfillment conditions. We can fall back upon the idea that experiential fulfillments are a phenomenological descriptive datum, and they cannot be conceived except by recourse to the idea of fulfillment conditions, as aspect of the experiences. Complementing the fulfillment conditions with PC will make no difference in this regard. On the contrary, it seems unproblematic to associate levels of PC with levels of fullness or evidence.

As for the "constitution" of veridicality and illusoriness, it is a somewhat different, complex matter: disappointments "announce" illusions, but I can sometimes be subject to an illusion even if it is never revealed to me in a disappointment. We shall set this issue aside. ${ }^{\mathrm{x}}$

4.

My final task in this paper is to argue for PC by appeal to the self-justification of perceptual experiences. Insofar as the ongoing PC debate is focused on the relations between PC and DC, I am effectively providing reasons to broaden and re-focus the current debate. Recall that we introduced this paper by inviting the reader to consider Morrison's idea that in cases like that of perceptually experiencing Isaac's approach, DC could and should be complemented by PC. In Section 5 of his paper, Morrison develops this line of thinking into an argument, of which Jacob Beck provides the following lucid summary,

(1) When you completely trust your experience, your doxastic confidence changes in step with your perceptual experience. For example, as Isaac approaches and your perceptual experience changes, your doxastic confidence that it is Isaac increases. (2) The most plausible explanation of why your doxastic confidence changes in step with your perceptual experience when you completely trust your experience is that your perceptual experiences assign perceptual confidences. For example, your doxastic confidence that it is Isaac increases because your perceptual experience assigns increasing confidence to the proposition that the approaching figure is Isaac. 
Thus,

(3) Perceptual Confidence is true; perceptual experiences assign perceptual confidences. For example, when Isaac is $50 \mathrm{~m}$ away, your perceptual experience assigns moderately high confidence to the proposition that the approaching figure is Isaac (or perhaps something more specific, like a 55-percent confidence that it is Isaac) (Beck 2019, pp. 2-3).

Having given this reconstruction of Morrison's argument, Beck contends that it depends not only on accepting the plausible view that perceptual experiences justify beliefs, but also on accepting something that Beck calls "the "importation model", which holds that when you completely trust your experience you simply "import" what your experience says into a belief, and thus come to believe exactly what you experienced" (Ibid., p. 9). Beck then argues that this problematic assumption seriously compromises Morrison's argument. ${ }^{\mathrm{xi}}$

Whatever the ultimate strengths and weaknesses of Morrison's argument, it appears to be closely bound up with the idea that perceptual experiences justify beliefs, conceived in terms of relations between PC and DC, perhaps involving quite a close alignment between levels of PC and DC. To appreciate how the present approach differs from Morrison's, consider that on our version of the Husserlian view, the levels of PC and DC may not be closely aligned at all. Remember that on our view, the levels of PC are closely associated with the levels of fullness, conceived as a kind of evidence to which perceptual experience is responsive as it unfolds, e.g., when I pick up a tennis ball and examine it from different perspectives, with my PC increasing, in regard to the ball's perceptual properties. In considering what bearing this has on my beliefs concerning the ball's perceptual properties, we need to keep in mind that a belief, and its justification, can persist when it has been detached from a perceptual situation like my examining the tennis ball.

Suppose that we are considering a perceptual experience with the content "This ball is yellow", and a belief with matching content. They come at levels of PC and DC respectively. It seems that to be entitled to more or less maintain my level of DC after detachment, I am not 
required to clutter my mind with anything like a complete memory of the experience of examining the ball, viz., in terms of coverage of different viewing angles, under certain lighting conditions. It consequently seems that we would do well to conceive of DC as being insensitive to such finegrained experiential detail. But we have offered a very different view of PC, viz., precisely as ongoingly responsive and finely attuned to such changeable fullnesses. There is therefore reason to believe that if there are both PC and DC, their levels are likely to come apart, not just postdetachment but even within perceptual situations.

I will clarify my view in another respect. Remember that I hold with Husserl that perceptual experiences gain fulfillments in the course of their unfolding, and are thus responsive to evidence. I have, in the above Section 2, proposed that if we accept this fulfillment-based view of perceptual experiences, it is natural, in individuating them, to view them as experiential processes which may involve various kinds of change, in particular, fulfillment. Following up on these thoughts, we may re-phrase our position, by saying that perceptual experiences are self-justifying. I borrow the expression from Susanna Siegel's recent groundbreaking discussion of the rationality of perception (Siegel 2017, p. 48). Let me explain what Siegel does with the idea of perceptual self-justification, and compare my view with hers. Siegel argues that, contrary to mainstream views which regard perceptual experiences as unjustified justifiers of beliefs, they should instead be regarded as justified justifiers. To further articulate the idea that perceptual experiences can both receive and pass on justification, Siegel attributes to them the property of epistemic charge, which she defines as " [a] property of experience that can be modulated by psychological precursors of the experience and transmitted to subsequent beliefs, and in virtue of which a subject's experience manifests an epistemic status" (Ibid., p. 41). ${ }^{\text {xii }}$ She takes epistemic charge to be grounded in the presentational phenomenology of the experiences, but modulated by their inferential relations with other beliefs 
upstream. Inferential relations with biased or other bad-making upstream beliefs can corrupt the experience, as when racially prejudiced beliefs conduce to my incorrectly experiencing a black man as holding a weapon. I may not be able to help having such an experience, but it is my duty to "quarantine" it when forming beliefs. On Siegel's view, "[b]oth perceptual experiences and the processes by which they arise can be rational or irrational" (Ibid., p. 15), in the sense of being epistemically appraisable. She further clarifies, "First, merely having a perceptual experience can benefit or detract from the subject's rational standing, and in that manner redound on the subject. Second, how the perceptual experience so redounds can depend on how the experience was formed" (Ibid., p. 16).

As part of her discussion of epistemic charge, Siegel introduces the idea of perceptual conservatism, in regard to which she remains neutral. It is a disjunction of two views, strong and intermediate perceptual conservatism. According to the former, perceptual experiences have "a pro tanto positive epistemic charge, where that amount can be augmented or reduced [even below the baseline, or zero], by other sources of positive or negative epistemic charge" (Ibid., p. 47). According to the latter view, the prima facie positive epistemic charge can be not only augmented or reduced, but just canceled out by the presence of defeaters or bad etiologies. According to perceptual conservatism, she argues, perceptual experiences are effectively self-justifying.

While I do not wish to make the nature of rationality a focus of the present paper, I would argue that perceptual self-justification in our sense, viz., by fulfillments and disappointments, leaves room for perception to be rational in something like Siegel's sense. When we speak of perceptual self-justification, we do, indeed, mean something different from Siegel: instead of a more or less synchronic consideration of perceptual experiences (such as goes naturally with the idea, embraced by Siegel, that contents are accuracy conditions), we bring into our purview the 
diachronicity of perceptual experiences (while considering the contents to be fulfillment conditions). Thus, even though we do not speak about perceptual experiences as being inferred from upstream beliefs, we are nevertheless able, like Siegel, to give consideration to perceptual experiences and the processes which give rise to them - the latter being the ways in which the experiences have unfolded, to reach the present phase.

But can we be held praise- or blameworthy for the way our perceptual experiences unfold? We appreciate fulfillments and disappointments for what they are, for their evidential significance, but we do not appear to be in control of fulfillments and disappointments. Instead, they are something that just happens to us, so that we are passive, relative to them. ${ }^{\text {xiii }}$ Nevertheless, we are able to pursue fulfillments, and open up to possible disappointments, viz., as we choose to look where we could be revealed as being mistaken. The importance of this is especially clear in the kinds of perception where we are experiencing several alternatives with different levels of PC. Let us call a way of pursuing fulfillments and opening up to disappointments, a perceptual attitude (not to be confused with the idea of an intentional mode). ${ }^{\text {xiv }}$ I believe that we can be held epistemically praiseworthy or blameworthy for cultivating certain perceptual attitudes. E.g., in the case of incorrectly experiencing the black man as carrying a weapon, our framework allows us to hold the perceiver blameworthy for not proceeding to take a more careful look.

Siegel believes that in this case the experience's epistemic charge is sub-zero, meaning that we are not entitled to use it in justifying beliefs. From our point of view, however, the epistemic charge should be regarded as amounting to two distinct items, two "epistemic charges", as it were, since we distinguish between the experience's epistemic significance with respect to the downstream experience and with respect to the downstream belief. In the given case, we may concur with Siegel that with regard to the justification of the belief that the man has a weapon, the 
epistemic charge of the perceptual experience is sub-zero, meaning that we should quarantine the experience. However, with respect to the self-justification of the ongoing perceptual experience, there is no way to just quarantine our present experience, not making use of the present fullness. On the contrary, we should be sensitive to what the present evidence is, as well as our present level of PC, and try to manage it by cultivating a certain attitude, viz., of seeking to take a more careful look. In other words, relative to perceptual self-justification, we should not regard the "epistemic charge" of the present experience as being sub-zero, but should appreciate its positive charge, and seek, as it were, to defuse it. On our version of strong perceptual conservatism, with regard to this kind of "epistemic charge", the requisite defeater needs to be generated within perceptual experience itself.

At the start of this section, we presented Beck's reconstruction of Morrison's argument in support of PC, and promised something quite different in its place. Now, the time has come to deliver on that promise. I believe that from the foregoing discussion, there emerges something like the following argument,

(1) If there is perception that is self-justifying, vis-à-vis motivated alternatives, then there are $\mathrm{PC}$.

(2) There is, indeed, such perception.

(3) There are PC.

The support for premise 1 comes mainly from Section 3, in light of additional clarifications in Sections 2 and 4. In Section 3, we distinguished two kinds of perception, making the point that while a level of fullness (or evidence) does not by itself determine a level of PC, it does determine a level of PC in cases where the perceptual experience involves motivated alternative possibilities. It seems that if we did not allow for levels of PC, as a kind of immediate reaction to the changeable 
levels of fullness (evidence), we would run the risk of losing our grasp on the kinds of experiences in which we negotiate several (motivated) alternatives, viz., insofar as there would not be a way to account for the organization, ordering of such alternatives. Premise 2 simply encapsulates the Husserlian view, as we have presented it in our Section 3, including by quoting from Husserl's discussion of alternately experiencing a man and a mannequin. If anybody disagrees with the Husserlian view on the grounds of some more general disagreement with the perspective of Husserlian phenomenology, then we are not prepared to launch into its defense here. But from premises 1 and 2, our conclusion follows.

\section{Conclusion}

In this paper, I have proposed a Husserlian account of perceptual confidence (PC), and argued for perceptual confidence by appeal to the self-justification of perceptual experiences. I first presented my Husserlian account with a focus on the notion of fulfillment, and the idea that the contents of perceptual experience are fulfillment conditions. I then showed that this account can be complemented by perceptual confidences. Finally, I developed a focus on the idea of perceptual self-justification, diverting the perceptual confidence debate from its pre-eminent concern with the relations between perceptual and doxastic confidences, and presented an argument for perceptual confidence. 
${ }^{i}$ A more detailed discussion of the basic aspects of the present view can be found, e.g., in Husserl 1997, Sections II and III.

${ }^{i i}$ For an articulation and defense of the accuracy-conditional view of content, see Siegel 2010, Part I.

iii Since I take such conditionals to capture fulfillment conditions, and fulfillment conditions to amount to contents, these examples may raise questions concerning how rich I take perceptual contents to be. For one influential approach to determining this, see Siegel 2010, Chapter 3. While I believe that the phenomenological approach favors views on which perceptual contents are rich, rather than poor, I will entirely bypass this issue in the present paper.

iv For Husserl's views of motivation, see Husserl 1997, § 51 and Ch. 10. For a recent discussion of the Husserlian notion of motivation, see Walsh 2017.

${ }^{\mathrm{v}}$ These changes can involve not just fulfillment, but also closer determination and re-determination. See Husserl 1997, § 29.

${ }^{\mathrm{vi}}$ In this regard, our view differs from Morrison's. Morrison clarifies that he neither conceives of PC as a normative thesis nor believes that "[PC] can shift only in response to evidence regarded as such" (Morrison 2016, pp. 28, 35).

vii The interpolated word in the last sentence of this quotation is the translators' contribution.

viii Experience and Judgment is neatly divided into Part I, dealing with pre-predicative experience, and Parts II and III, dealing with predicative thought.

${ }^{i x}$ I would, at this juncture, try to address an important concern raised by a reviewer of this paper, viz., that the issue of conceptualism vs. non-conceptualism about perceptual contents should be regarded as relevant to the main purport of my paper, and that a failure to discuss it therefore amounts to a significant lacuna. E.g., if Morrison's view is nonconceptualist and mine is conceptualist, that might be a reason to prefer Morrison's view to mine, especially in view of the criticisms that Walter Hopp has made of conceptualism, Husserlian and other (Hopp 2011).

But it is not obvious to me that there is such a difference between my view and Morrison's, providing strong grounds to choose one view over the other. (I would also remind the reader that I am not arguing against Morrison's views in this paper.) Morrison deals in propositional perceptual content (Morrison 2016, pp. 36-41). Although he questions the idea of accuracy conditions, he regards it as possible to cash out propositional content in terms other than accuracy conditions (Ibid., pp. 40-41). The notion of non-conceptual content is not part of his discussion-even if his views might leave room for it. I, on my part, am ready to accept that, in the cases at hand, perception at least has a conceptual (a predicative, a propositional) element to it - although I cannot go as far as to altogether deny the existence of non-conceptual content. My view is thus situated somewhere in the vicinity of what Hopp calls "weak experiential conceptualism" (Hopp 2011, p. 37).

I have just pointed out that, for Husserl, perceptual confidence has a basis in aspects of pre-predicative experience - which Husserl regards as being structured not in terms of concepts but "types" (Husserl 1973, pp., 36, 317-318. See also Lohmar 2003.). Given the views I advance in my paper, I am bound to recognize a non-conceptual aspect of perceptual content. Thus, even though I claim perception to be rational, I do not conceive of this rationality entirely, or primarily, in terms of linguistically expressible reasons, but, rather, in terms of a kind of evidence that is not readily detachable from perceptual situations, viz., due to involving fine gradations of fullness and emptiness. The contents of beliefs and perceptual experiences must, accordingly, come apart, at least to some extent.

I wish to make two quick comments, to at least make room for such a view, given Hopp's critique of a Husserlian conceptualism. The first is that, regarding Hopp's objections to aspects of the view that Husserl advances in the $6^{\text {th }}$ Logical Investigation (Husserl 1970), the debate continues. Chad Kidd and Pirui Zheng have recently advanced nuanced conceptualist readings of the $6^{\text {th }}$ Investigation, responding to Hopp's critical considerations (Hopp 2008 and 2011, Kidd 2019, Zheng 2019). The second point is that I approach perceptual content and fulfillment from a rather different perspective from Hopp's, and my perspective seems not illegitimate. Almost throughout his book, Hopp's concern is with what he calls "epistemic fulfillment", i.e., the way that a perceptual experience justifies a belief or judgment, viz., based on the model that Husserl puts forward in the $6^{\text {th }}$ Investigation. Such "epistemic fulfillment" takes place by way of a higher-level "act" of synthesis, involving perceptual content, on the one hand, and the content of the belief or judgment, on the other (Hopp 2011, pp. 191-201). Only at the end of his book does Hopp acknowledge the existence, besides such "epistemic fulfillment", of the kind of "intuitive fulfillment" that takes place when empty aspects of a perceptual experience become (increasingly) fulfilled in the course of that experience (Ibid., 205-206. But see also Hopp 2010.). In other words, an "intuitive fulfillment" is not a higher-level synthesis of 
distinct signitive and intuitive "acts", but a one-level phenomenon of an "act's" transition from lesser to greater degrees of intuitive fullness.

We could say that Hopp's view of perceptual content is developed with a regard for his central concern with "epistemic fulfillment", while mine is based on the idea of "intuitive fulfillment". However, I am uneasy with this formulation, since I believe that all fulfillment is both intuitive and, at least in a broader sense, epistemic. Regarding intuitiveness, I would not know how to conceive of fulfillment except as conferral of intuitiveness or fullness. The Husserlian idea of intuition is versatile enough allow for intuitive fulfillment of complex signitive acts and linguistic meanings (See, e.g., Tugendhat 1970, especially pp. 46-63.) As for the epistemic import of fulfillment, it brings us to the main contention of my paper. Hopp accepts the prevalent view that perceptual experiences are never epistemically justified (Hopp 2011, p. 107), whereas I seek to question this view — and so does Susanna Siegel, as can be seen below. ${ }^{\mathrm{x}} \mathrm{I}$ discuss this topic in Laasik 2019, Section 4.

${ }^{x i}$ For Beck's criticisms of the importation model, see Beck 2019, Section 5. From his footnote 7, we also learn that Beck is, for similar reasons, skeptical of Jessie Munton's recent argument for PC (Ibid., p. 13). See also Munton 2016.

${ }^{x i i}$ For Siegel's discussion of this idea, aspects of which are rendered in the main body of my text, see Siegel 2017, Ch. 3.

xiii For Siegel's critical discussion of the putative passivity of perceptual experiences, see Siegel 2017, pp. 31-38.

${ }^{\text {xiv }}$ I borrow this expression ("Einstellung") and perhaps also the rough idea from Herbert Leyendecker, an early phenomenologist who was a member of the Munich and Göttingen Phenomenological Circles. While attitudes are an important concern for Leyendecker, he does not define the term, but merely elucidates it by offering miscellaneous examples and clarifications. E.g., we are told that the attitude of searching "works like a sieve, which lets fall through everything that does not fit, so that only that is spotted wherein I, in my attitude, as I search, "remain hanging" with my glance" (Leyendecker 1913, p. 52).

Tracing the notion back to the psychology of Leyendecker's day, Kevin Mulligan elucidates it as "the higher-order unity of modes, tendencies, and dispositions which is often the function of determinate types of interest and attention" (Mulligan 1995, p. 204). Mulligan regards Leyendecker's incorporation of this notion into philosophy as a fruitful, indeed "elegant development of Husserl's account of the connection between optimality and interest" (Ibid.). 


\section{Bibliography}

Beck, J. (2019). On Perceptual Confidence and "Completely Trusing Your Experience". Analytic Philosophy, O(0), 1-15.

Hopp, W. (2008). Husserl on Sensation, Perception, and Interpretation. Canadian Journal of Philosophy, 38(2), 219-246.

Hopp, W. (2010). How To Think About Non-Conceptual Content. The New Yearbook for Phenomenology and Phenomenological Philosophy, 10(1), 1-24.

Hopp, W. (2011). Perception and Knowledge: A Phenomenological Account. Cambridge, UK: Cambridge University Press.

Husserl, E. (1969). Formal and Transcendental Logic. (Dorion Cairns, Trans.) The Hague: The Netherlands: Martinus Nijhoff.

Husserl, E. (1970). Logical Investigations (Vol. 2). London: Routledge and Kegan Paul.

Husserl, E. (1973). Experience and Judgment. (Ludwig Landgrebe, Ed.; James S. Churchill and Karl Ameriks, Trans.) Evanston, IL: Northwestern University Press.

Husserl, E. (1997). Thing and Space. Lectures of 1907 (Edmund Husserl Collected Works, Vol. VII). (R. Rojcewicz, Ed., \& R. Rojcewicz, Trans.) Dordrecht, Holland: Kluwer Academic Publishers.

Kidd, C. (2019). Re-examining Husserl's Conceptualism in the Logical Investigations. Archiv für Geschichte der Philosophie, 101(3), 407-444.

Laasik, K. (2019). Attitudes and Illusions: Herbert Leyendecker's Phenomenology of Perception. Continental Philosophy Review, 52(3), 279-298.

Leyendecker, H. (1913). Zur Phänomenologie der Täuschungen. Halle an der Saale, Germany: Buchdruckerei des Waisenhauses. 
Lohmar, D. (2003). Husserl's Type and Kant's Schemata: Systematic Reasons for Their Correlation or Identity. In D. E. Welton, The New Husserl: A Critical Reader (pp. 93-124). Bloomington and Indianapolis, IN: Indiana University Press.

Morrison, J. (2016). Perceptual Confidence. Analytic Philosophy, 57(1), 15-48.

Mulligan, K. (1995). Perception. In B. Smith, \& D. W. Smith (Eds.), The Cambridge Companion to Husserl (pp. 168-238). Cambridge, UK: Cambridge University Press.

Munton, J. (2016). Visual Confidences and Direct Perceptual Justification. Philosophical Topics, 44(2), 301-326.

Siegel, S. (2010). The Contents of Visual Experience. Oxford, UK: Oxford University Press.

Siegel, S. (2017). The Rationality of Perception. Oxford, UK: Oxford University Press.

Tugendhat, E. (1967). Der Wahrheitsbegriff bei Husserl und Heidegger. Berlin, Germany: Walter de Gruyter.

Walsh, P. J. (2017). Motivation and Horizon: Phenomenal Intentionality in Husserl. Grazer Philosophische Studien, 94(3), 410-435.

Zheng, P. (2019). Is Husserl a Conceptualist? Re-reading Husserl's Sixth Logical Investigation. Husserl Studies, 35, 249-263. 